Aletheia

ISSN: $1853-3701$

publicaciones@fahce.unlp.edu.ar

Universidad Nacional de La Plata

Argentina

\title{
Coloquio internacional: "El imaginario testimonial en el Cono Sur. Las configuraciones desde el género". Universidad Nacional de La Plata, La Plata, 4 y 5 de noviembre de 2019.
}

\author{
Codaro, Laura; Inama, Ramón Oscar \\ Coloquio internacional: "El imaginario testimonial en el Cono Sur. Las configuraciones desde el género". \\ Universidad Nacional de La Plata, La Plata, 4 y 5 de noviembre de 2019. \\ Aletheia, vol. 10, núm. 19, 2019 \\ Universidad Nacional de La Plata, Argentina \\ DOI: https://doi.org/10.24215/18521606e038
}

Esta obra está bajo una Licencia Creative Commons Atribución-NoComercial-Compartirlgual 4.0 Internacional 
Reseñas, crónicas y notas de opinión

\section{Coloquio internacional: "El imaginario testimonial en el Cono Sur. Las configuraciones desde el género". Universidad Nacional de La Plata, La Plata, 4 y 5 de noviembre de 2019.}

Laura Codaro

DOI: https://doi.org/10.24215/18521606e038

Universidad Nacional de La Plata, Argentina

lauritacodaro@hotmail.com

Ramón Oscar Inama

Universidad Nacional de La Plata, Argentina

romaninama@yahoo.com.ar

Durante los días 4 y 5 de noviembre de 2019 se desarrollaron en la ciudad de La Plata, más precisamente en el Centro de Posgrado Sergio Karakachoff que pertenece a la Universidad Nacional de La Plata, un conjunto de charlas, mesas de debate, discusiones y presentaciones de libros que nuclearon mayoritariamente a reconocidas investigadoras que, desde hace algunas décadas y desde diferentes disciplinas, estudian el testimonio y, en mayor o menor medida, sus vínculos con las cuestiones de género. El encuentro fue organizado por las Dras. Teresa Basile y Miriam Chiani, dos docentes e investigadoras que forman parte del Centro de Teoría y Crítica literaria de la Facultad de Humanidades y Ciencias de la Educación (UNLP) y de múltiples formas alientan el trabajo en torno a diferentes problemáticas que ligan a la literatura con la última dictadura cívico-militar argentina, piensan los lazos entre el arte y la violencia en el Cono Sur, entre otros puntos de interés que están plasmados en sus distintos proyectos de investigación acreditados.

En este caso en particular, el encuentro estuvo motivado, además, por los diálogos entre Argentina e Italia, que surgieron de intercambios anteriores entre colegas y universidades de ambos países. Éstos buscaban observar comparativamente diferentes aspectos de los regímenes totalitarios y de las posteriores políticas reparatorias, pero también condujeron a repensar las consecuencias de las migraciones, las experiencias traumáticas vividas allí y luego aquí en Argentina, el desarrollo de los procesos judiciales, etc. No obstante, lejos de tratarse de la lectura de trabajos que miran hacia el pasado, los debates que fueron surgiendo intentaban reflexionar sobre distintas problemáticas actuales en pos de imaginar nuevos proyectos: la escasez de escritoras en los programas de las asignaturas universitarias, la necesidad de conformar un archivo de madres literarias, la posibilidad de observar la dictadura cívico-militar argentina desde el exterior, el desafío de observar comparativamente las características de la literatura producida en torno al testimonio en Argentina y en Italia, fueron algunas de las ideas que se compartieron y se conversaron a partir de las exposiciones de los ponentes.

Cabe destacar que las mesas de discusiones, las presentaciones de los libros y hasta las charlas más informales entre compañeros, colegas y amigos estuvieron atravesadas por temas comunes entre los que sobresalió la maternidad. En efecto, encontramos la maternidad en la oscuridad del centro clandestino de detención pero también como salvación después del cautiverio; observamos la maternidad en la militancia de los sesenta y setenta; analizamos los dilemas en torno a la reproducción que se plantean los personajes de distintas obras literarias; nos conmovimos en torno al arrebato de la vida de un hijo... en fin, el encuentro en su totalidad nos permitió mirar y repensar, una vez más, a las mujeres y las madres que luchan y resisten.

El coloquio se inauguró con las palabras de Ana Barletta, coordinadora de la Maestría en Historia y Memoria (UNLP), quien subrayó la importancia de escuchar y estudiar las memorias, habló de la dura 
represión que sufrió la ciudad de La Plata durante la última dictadura y propuso reflexionar en torno al movimiento de mujeres que, parafraseando su discurso, es inspirador y a la vez, nos convoca a cooperar como mujeres, universitarias, docentes y militantes. A continuación, tomó la palabra Miriam Chiani, quien señaló la producción existente en torno a las investigaciones sobre género y memoria y la necesidad de seguir leyendo, conversando y produciendo. Con este impulso comenzaron a presentarse y comentarse un vasto, heterogéneo y prolífico conjunto de trabajos en los que participaron investigadores de diferentes partes del país y extranjeros, algunos cuentan con una larga trayectoria y otros iniciaron su recorrido hace algunos años, lo cual favoreció el intercambio multicultural e intergeneracional. Compartieron sus producciones Leonor Arfuch, Nora Domínguez, Emmanuel Kahan, Julieta Lampasona, Paula Simón, Mariela Peller, Emilia Perassi, Rossana Nofal, Susana Rosano, María Laura de Arriba, Claudia Bacci, Victoria Daona, Paola Martínez y María Rosa Lojo. Esta última habló de su infancia, su familia, su producción literaria y más específicamente de su libro Todos éramos Hijos.

Sin dudas, el momento más conmovedor tuvo lugar hacia el final de la jornada del primer día, en la presentación de la Serie Diálogos entre Italia y Argentina, dirigida por Emilia Perassi y Camilla Cattarulla, de la editorial EDUVIM. Allí Teresa Basile y Emilia Perassi intercambiaron algunas ideas sobre la migración de italianos hacia Argentina, los motivos de la "diáspora", las condiciones de recepción de los que arribaban al país, las representaciones de estas migraciones, las experiencias traumáticas en ambos países y principalmente las formas que adoptó la literatura frente a este conjunto de fenómenos y procesos. Luego Ramón Inama, en su doble condición de investigador e hijo de desaparecidos, comenzó a dialogar con Vera Jarach y Eleonora Smolensky, quienes fueron invitadas a presentar su libro Tantas voces, una historia. Italianos judios en la Argentina 1938-1945, un texto de 1999, reeditado en esta oportunidad por EDUVIM en 2018. Ambas autoras fueron protagonistas de lo que narran en su libro. Tanto Vera como Eleonora llegaron desde Italia siendo niñas. En una emotiva charla dieron detalles de sus experiencias como perseguidas -en su país natal por su origen judío- y como migrantes. Una vez instaladas aquí en Argentina y ya en su lugar de madres, también sufrieron la persecución de sus propias hijas, en este caso por la dictadura argentina de 1976-1983. El caso de Vera es aún más desgarrador: se trata de una mujer que por partida doble fue golpeada por regímenes autoritarios, ya que no sólo perdió a su abuelo en los campos de exterminio nazi allá en Europa, sino que en 1976 su única hija, Franca, fue secuestrada con apenas 18 años, así pasó a integrar la larga lista de desaparecidos por la dictadura Argentina. Vera emprendió una incansable búsqueda desde Madres de Plaza de Mayo y realizó innumerables acciones en defensa de los Derechos Humanos.

El diálogo entre estas tres personas cuyas vidas fueron atravesadas por distintas experiencias traumáticas de persecución y desaparición cautivó al público porque, además de hablar de antisemitismo, represión y dictadura, pensaron en todo lo que queda por hacer y luchar. Especialmente Vera, a través de un lenguaje ameno y cercano, logró aunar en el relato de su historia de vida muchas de las ideas que generaron este Coloquio: el testimonio de las violencias del Cono Sur ejercidas en este caso sobre mujeres, que desde su experiencia traumática, nos invitan a reflexionar sobre las múltiples maneras de reconvertir ese dolor en resistencia. Indudablemente, al calor de los sucesos de este corto tiempo que nos separa del Coloquio en el que nuestro continente latinoamericano viene sufriendo represión, tortura y muerte por parte del Estado, todas estas ideas compartidas se resignifican extraordinariamente y se transforman, por qué no, en estrategias para enfrentar el autoritarismo y la violencia. 


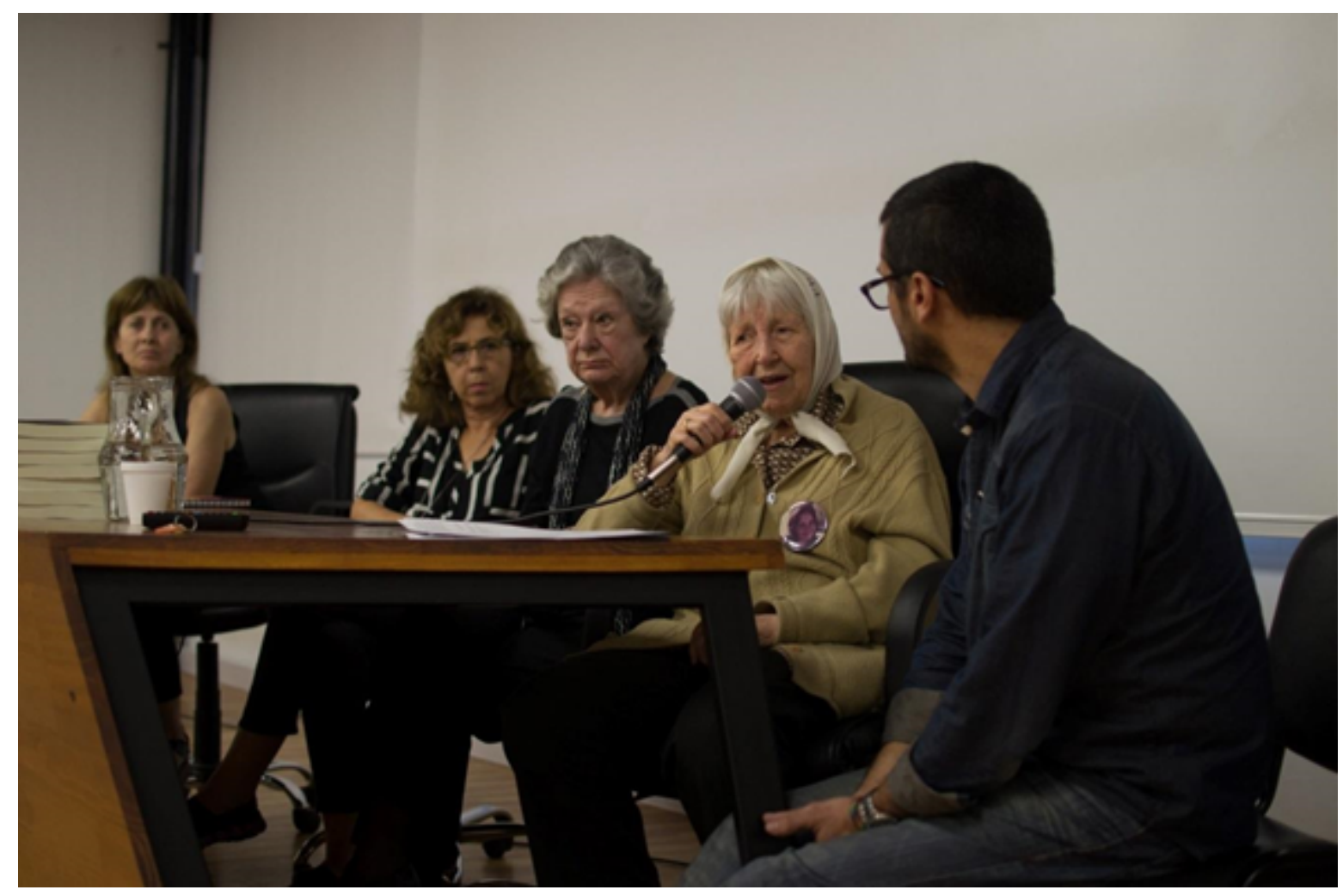

Fotografía: Gregorio Bjerring

\section{BY-NC-SA}

